\title{
Analysis of influence of heat exchange conditions on the outer surface of the lithium- ion battery to electrolyte temperature under the conditions of high current loads
}

\author{
Alexander Krasnoshlykov ${ }^{1, *}$ \\ ${ }^{1}$ National Research Tomsk Polytechnic University, 634050 Tomsk, Russia
}

\begin{abstract}
Numerical analysis of thermal conditions of a lithium-ion battery using the software package ANSYS Electric and ANSYS Fluent has been carried out. Time dependence of the electrolyte temperature on the various heat exchange conditions on the outer surface has been obtained.
\end{abstract}

\section{Introduction}

Lithium-ion batteries play an important role as a source energy in a variety of applications (motor transport, aviation and space equipment) and have prospects for development through the low weight, high energy and power density [1,2]. However, a major obstacle to the wide use of batteries of this type is the flammability and low performance at increasing temperature due to thermal runaway $[1,2]$.

Thermal runaway of the battery is the effect which occurs when electrolyte temperature increases and the current flowing through the battery can rise to values approaching the short-circuit current [2]. Thermal runaway is able to affect the safety of the use of vehicles (e.g., aircraft [1]). Thermal runaway occurs at a combination of factors: the electrolyte temperature rise due to insufficient battery heat exchange with the environment; low level of electrolyte in the battery cell; aging active electrode mass [2].

The experiments with accumulators reduce to determining the temperature of the surface under certain conditions of their use [3]. It should be noted that when designing a typical lithium-ion battery, it is necessary to take into account the heat release during the passage of an electric current through plates (Joule heat) [4]. To solve this kind of complex problems, it is most expedient to apply methods of mathematical modeling of heat transfer processes in the material of solid plates and the electrolyte volume of the battery based on solving the systems of mass transfer equations, momentum and energy [5] Joel heat.

The purpose of the work is mathematical modeling of temperature distributions in the accumulator under various heat exchange conditions on the external vertical surface.

\footnotetext{
Corresponding author: krasnas@tpu.ru
} 


\section{Formulation of the problem}

A typical segment of a lithium-ion battery, including copper and aluminum plates, a liquid layer of electrolyte between them and a solid wall is considered (Fig.1b).

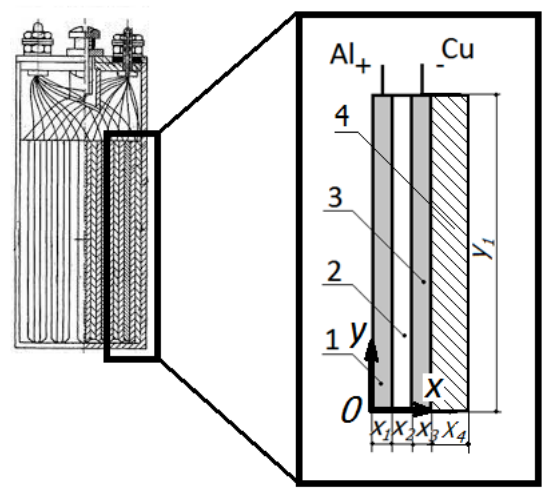

a). b).

Fig. 1. a). General view of the region of the solution; b). The considered segment of the battery. 1 positive electrode (aluminium plate); 2 - liquid electrolyte (LiPF6); 3 - negative electrode (copper plate); 4 - battery wall (polypropylene).

In the formulation of the problem, the possible release of heat as a result of exothermic chemical reactions of the interaction of electrolyte and electrode materials was not taken into account.

Joule heat is computed using the vector potential method [6]:

$$
Q^{j}=\frac{1}{n} \sum_{i=1}^{n}[\rho]\left\{J_{t i}\right\} \cdot\left\{J_{t i}\right\}
$$

where $Q^{j}-$ Joule heat per unit volume;

$n$ - number of integration points;

$[\rho]$ - resistivity matrix;

$\left\{J_{t i}\right\}$ - total current density in the element at integration point $i$.

It was assumed that the heat release in the plates was distributed uniformly along the $x$ and $y$ directions.

The equations of continuity, momentum and energy for a layer of liquid electrolyte:

$$
\begin{gathered}
\frac{\partial \rho}{\partial t}+\frac{\partial(\rho u)}{\partial x}+\frac{\partial(\rho v)}{\partial y}=0 \\
\frac{\partial \rho_{2} u_{2}}{\partial t}+\frac{\partial\left(\rho_{2} u_{2} u_{2}\right)}{\partial x}+\frac{\partial\left(\rho_{2} v_{2} u_{2}\right)}{\partial y}=\rho_{2} g_{x}-\frac{\partial P_{2}}{\partial x}+\frac{\partial}{\partial x}\left(\mu_{2} \frac{\partial u_{2}}{\partial x}\right)+\frac{\partial}{\partial y}\left(\mu_{2} \frac{\partial u_{2}}{\partial y}\right) \\
\frac{\partial \rho_{2} v_{2}}{\partial t}+\frac{\partial\left(\rho_{2} u_{2} v_{2}\right)}{\partial x}+\frac{\partial\left(\rho_{2} v_{2} v_{2}\right)}{\partial y}=\frac{\partial P_{2}}{\partial y}+\frac{\partial}{\partial x}\left(\mu_{2} \frac{\partial v_{2}}{\partial x}\right)+\frac{\partial}{\partial y}\left(\mu_{2} \frac{\partial v_{2}}{\partial y}\right) \\
\rho_{2} C_{p 2}\left(\frac{\partial T_{2}}{\partial t}+u_{2} \frac{\partial T_{2}}{\partial x}+v_{2} \frac{\partial T_{2}}{\partial y}\right)=\lambda_{2}\left(\frac{\partial^{2} T_{2}}{\partial x^{2}}+\frac{\partial^{2} T_{2}}{\partial y^{2}}\right)
\end{gathered}
$$


Equation of thermal conductivity for plates and the battery wall:

$$
\begin{aligned}
& \rho_{1} C_{p 1} \frac{\partial T_{1}}{\partial t}=\lambda_{1}\left(\frac{\partial^{2} T_{1}}{\partial x^{2}}+\frac{\partial^{2} T_{1}}{\partial y^{2}}\right) \\
& \rho_{3} C_{p 3} \frac{\partial T_{3}}{\partial t}=\lambda_{3}\left(\frac{\partial^{2} T_{3}}{\partial x^{2}}+\frac{\partial^{2} T_{3}}{\partial y^{2}}\right) ; \\
& \rho_{4} C_{p 4} \frac{\partial T_{4}}{\partial t}=\lambda_{4}\left(\frac{\partial^{2} T_{4}}{\partial x^{2}}+\frac{\partial^{2} T_{4}}{\partial y^{2}}\right)
\end{aligned}
$$

where $u, v$ - the velocity components in the projection on the axis $x, y$, respectively; $P$ pressure; $T$ - temperature; $\rho$ - density; $x, y$-Cartesian coordinates; $t$ - time; $C_{p}$ - heat capacity; $g$ - acceleration of gravity; $\lambda$ - coefficient of thermal conductivity; $\mu$ - dynamic viscosity; indices 1, 2, 3, 4 - correspond to aluminum, electrolyte, copper and polypropylene.

The initial conditions for the system of equations (1-7) are as follows: $u(x, y)=0 ; T(x, y)=T 0 ; P(x, y)=P 0$.

The boundary conditions for the equations (1-7) have the form:

$$
\begin{aligned}
& x=0,0<y<y_{1} \quad \frac{\partial T_{1}}{\partial x}=0 ;
\end{aligned}
$$

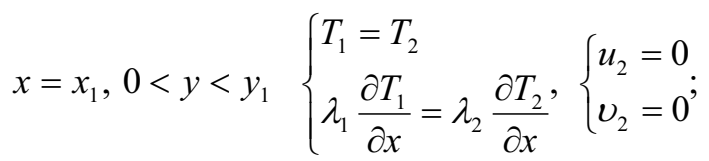

$$
\begin{aligned}
& x=x_{1}+x_{2}, 0<y<y_{1}\left\{\begin{array} { l } 
{ T _ { 2 } = T _ { 3 } } \\
{ \lambda _ { 2 } \frac { \partial T _ { 2 } } { \partial x } = \lambda _ { 3 } \frac { \partial T _ { 3 } } { \partial x } , }
\end{array} \left\{\begin{array}{l}
u_{2}=0 \\
v_{2}=0
\end{array} ;\right.\right. \\
& x=x_{1}+x_{2}+x_{3}, 0<y<y_{1}\left\{\begin{array}{l}
T_{3}=T_{4} \\
\lambda_{3} \frac{\partial T_{3}}{\partial x}=\lambda_{4} \frac{\partial T_{4}}{\partial x}
\end{array}\right. \\
& x=x_{1}+x_{2}+x_{3}+x_{4}, 0<y<y_{1} \lambda_{4} \frac{\partial T_{4}}{\partial x}=\alpha\left(T_{4}-T_{O C}\right) \\
& y=0,0<x<x_{1} \quad \lambda_{1} \frac{\partial T_{1}}{\partial y}=0 ; \quad y=0, x_{1}<x<x_{2} \quad \lambda_{2} \frac{\partial T_{2}}{\partial y}=0,\left\{\begin{array}{l}
u_{2}=0 \\
v_{2}=0
\end{array}\right. \\
& y=0, x_{2}<x<x_{3} \quad \lambda_{3} \frac{\partial T_{3}}{\partial y}=0 ; \quad y=0, x_{3}<x<x_{4} \lambda_{4} \frac{\partial T_{4}}{\partial y}=0
\end{aligned}
$$




$$
\begin{array}{cc}
y=y_{1}, 0<x<x_{1} \lambda_{1} \frac{\partial T_{1}}{\partial y}=0 ; & y=y_{1}, x_{1}<x<x_{2} \lambda_{2} \frac{\partial T_{2}}{\partial y}=0,\left\{\begin{array}{l}
u_{2}=0 \\
v_{2}=0
\end{array}\right. \\
y=y_{1}, x_{2}<x<x_{3} \lambda_{3} \frac{\partial T_{3}}{\partial y}=0 ; & y=y_{1}, x_{3}<x<x_{4} \lambda_{4} \frac{\partial T_{4}}{\partial y}=0 .
\end{array}
$$

\section{Results and Discussion}

Numerical modeling of heat transfer processes during the flow of direct current through the battery plates (Fig.1) is carried out using the ANSYS Electric and ANSYS Fluent software packages. Geometric dimensions of the solution region: the height of the plates $\left(0<y<y_{1}\right)$ is $140 \mathrm{~mm}$, the thickness of each element (aluminum, copper plates and electrolyte layer) is $0.5 \mathrm{~mm}$, the wall thickness is $2 \mathrm{~mm}[7,8]$.

The following variants of load current on the battery are adopted: $I_{n}=50 \mathrm{~A}, I_{n}=60 \mathrm{~A}$, $I_{n}=70 \mathrm{~A}$ [4]. As the electrolyte is adopted $\mathrm{LiPF}_{6}$ [7]. The temperature of thermal decomposition of this electrolyte is $125^{\circ} \mathrm{C}$ [8], however, it should be noted that already at $60^{\circ} \mathrm{C}$ in the volume of electrolyte chemical reactions occur, described in [3, 4], which can lead to thermal overclock of the battery.

Figure 2 shows the dependence of the average temperature of the electrolyte on time with a heat-insulated battery case. It can be seen that in the absence of cooling from the surface of the wall of the battery case and the current load above the nominal (>50 A), the temperature reaches critical values $\left(60^{\circ} \mathrm{C}\right)$ in $800 \mathrm{~s}$.

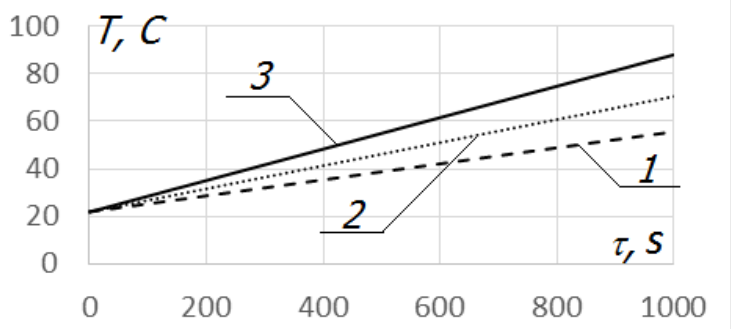

Fig. 2. Dependence of the battery electrolyte temperature on time with different current load (no cooling). $1-I_{n}=50 \mathrm{~A}, 2-I_{n}=60 \mathrm{~A}, 3-I_{n}=70 \mathrm{~A}$.

When the battery surface is cooled $\left(\alpha=5 \mathrm{~W} /\left(\mathrm{m}^{2} \cdot \mathrm{K}\right)\right.$ at the boundary) the temperature of the electrolyte rises slower. Up to a constant value, the temperature rises to $4000 \mathrm{~s} \mathrm{(Fig.} \mathrm{3a).}$ With the considered current load versions of $50 \mathrm{~A}, 60 \mathrm{~A}, 70 \mathrm{~A}$ and a heat transfer coefficient of $5 \mathrm{~W} /\left(\mathrm{m}^{2} \cdot \mathrm{K}\right)$ the electrolyte temperature in the established mode is higher than the nominal one and is $74,3{ }^{\circ} \mathrm{C}, 97,3{ }^{\circ} \mathrm{C}$ and $124,5{ }^{\circ} \mathrm{C}$, respectively.
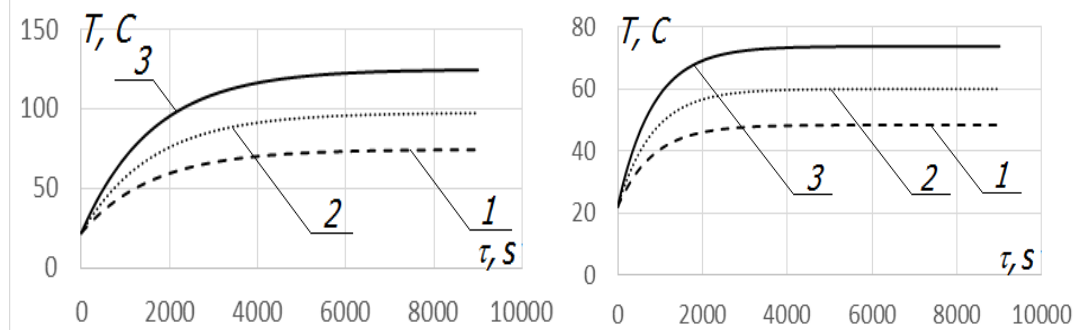

Fig. 3. Dependence of the battery electrolyte temperature on time at different current load at a). $\alpha=5$ $\left.\left.\mathrm{W} /\left(\mathrm{m}^{2} \cdot \mathrm{K}\right) ; \mathrm{b}\right) . \alpha=10 \mathrm{~W} /\left(\mathrm{m}^{2} \cdot \mathrm{K}\right)\right) .1-I_{n}=50 \mathrm{~A}, 2-I_{n}=60 \mathrm{~A}, 3-I_{n}=70 \mathrm{~A}$. 
With intensive heat transfer from the wall surface of the battery case $\left(\alpha=10 \mathrm{~W} /\left(\mathrm{m}^{2} \cdot \mathrm{K}\right)\right)$ the electrolyte temperature rises to above the regulatory values only at a load current of 70 $\mathrm{A}$ and is $73,7^{\circ} \mathrm{C}$ (Fig.3b).

The results of the performed studies show that under conditions of sufficiently intense heat generation in electrodes plates caused by high current loads. It is possible to ensure the level of electrolyte temperatures allowed by the battery operation regulations due to the heat sink from the outer surface of the battery case. At the same time, it is enough to provide conditions for the coefficients of heat transfer from these surfaces to reach 10 $\mathrm{W} /\left(\mathrm{m}^{2} \cdot \mathrm{K}\right)$.

\section{Conclusion}

Based on the results of numerical modeling of convective-conductive heat transfer, it is established that an increase in the heat transfer intensity from the wall surface of the battery cabinet in the range of variation of the coefficient $\alpha$ from 5 to $10 \mathrm{~W} /\left(\mathrm{m}^{2} \cdot \mathrm{K}\right)$ leads to a significant decrease in the temperatures of the liquid electrolyte by $26{ }^{\circ} \mathrm{C}$ at a constant current load of $50 \mathrm{~A}$ compared with the thermal insulation on the outer contour of the battery case. At $I_{n}=60 \mathrm{~A}$ and $70 \mathrm{~A}$ the temperature decreases in the cooling conditions at 37 ${ }^{\circ} \mathrm{C}$ and $51{ }^{\circ} \mathrm{C}$, respectively.

With a current load of not more than 60 A and a heat transfer coefficient of 10 $\mathrm{W} /\left(\mathrm{m}^{2} \cdot \mathrm{K}\right)$, the temperatures of both the battery surface and its electrolyte do not exceed the specified temperature values $\left(60^{\circ} \mathrm{C}\right)$.

Based on the analysis of the results of the numerical simulation, it can be concluded that even a relatively moderate heat dissipation from the surface of the outer wall has a considerable influence on the performance of the battery.

The reported research was supported by Russian Federation President Grant for state support of the Russian Federation leading scientific schools SS-7538.2016.8 (No.14.Y31.16.7538-SS).

\section{References}

1. D.E. Bruskin, Electric power supply of aircrafts (Higher School, Moscow,1988) [in Russian]

2. J. Van Mierlo, G. Maggetto, J. Automobile Engineering, 36, 583 (2003)

3. S.G. Rebrov, S.V. Yanchur, V.S. Mansurov, S.A. Moskovkin, Proceedings of the MAI, 72 (2014) [in Russian]

4. A. Sambaa, N. Omar, Electrochimica Acta, 117, 246 (2014)

5. G.V. Kuznetsov, Al-Ani, M.A. Sheremet, J. Eng. Thermophys. 201 (2011)

6. Ansys Help. FLUENT Theory Guide.

7. C. Forgez, D. Vinh Do, G. Friedrich, M. Morcrette, C. Delacourt, J. Power Sources, 195 (9) ,2961 (2010)

8. R. Younesi, G. M. Veith, P. Johansson, Energy \& Environmental Science 8, 1905 (2015) 